Die Wirkungen v. Muscarin u. Atropin auf d. Schweissdrüsen d. Katze. 501

(Aus dem physiologischen Laboratorium in Zürich.)

\title{
Die Wirkungen von Muscarin und Atropin auf die Schweissdrüsen der Katze.
}

(Ein weiterer Beitrag zur Lehre vom doppelseitigen Antagonismus zweier Gifte.)

Von

D. Trümpy und B. Luchsinger.

In Band XV dieses Archivs hatte der Eine von uns Versuche mitgetheilt, welche in einfachster und eindeutigster Weise den alten Streit über den wechselseitigen Antagonismus zweier Gifte völlig entschieden. Wenn auch Atropin die Reizwirkung einer bestimmten Gabe Pilocarpin vollkommen zu lähmen vermag, so stellt gleichwohl eine noch grössere Menge von Pilocarpin die Erregbarkeit und Leistungsfähigkeit der Schweissdrüsen wieder her.

Seither hat Marm $\dot{e}^{1}$ ) Widerspruch erhoben, er gibt zwar zu, dass Atropin eine durch Pilocarpin hervorgerufene Schweisssecretion sistirt, konnte sich aber von einem doppelseitigen Antagonismus beider Gifte nicht überzeugen; - Grund genug, diesen so wichtigen Versuch nochmals aufzunehmen. Da jedoch nur der zweite Theil unseres Satzes - die Wiederherstellung der durch Atropin gelähmten Drïsenerregbarkeit mittelst Pilocarpin - streitig sein konnte, beschränkten wir unsere jetzigen Versuche auch ausschliesslich auf diesen Punkt. Dieselben haben uns ebenso positive Ergebnisse gebracht wie die früheren, sie wurden meist in Gegenwart mehrerer Augenzeugen ausgeführt, von welchen Herrn Professor Hermann zu nennen genügen möge.

1) Göttinger Nachrichten. 1878. Nr. 3. 
Versuche $\left.{ }^{1}\right)$.

Man durchschneide einer jungen Katze in Aether- oder Chloroformnarcose beide Hüftnerven, lege Ligaturen an ihre peripheren Stümpfe und bringe zur Ruhezeit dieselben zurück in die Tiefe der Wunde, schliesse diese selbst mit kleinen Klemmpincetten.

Von der Leistungsfähigkeit der. Drüsen hat man sich ohne Weiterès schon durch das Schwitzen aller vier Pfoten beim Aufbinden des Thieres etc. überzeugen können. Nun injicire man $0,0015 \mathrm{gr}$ Atropin. sulphuric. subcutan, unter die Rïckenhaut z. B., und prüfe nach ca. 10-15 Min. auf das Schweissvermögen der Hinterpfoten. Häufig genügt nämlich schon diese, also nur die Hälfte der früher als minimal angegebenen Dose, um selbst stärkste tetanische Reizungen des Hüftnerven zur Auslösung weiteren Schwitzens unfähig zu machen. Ist diess ausnahmsweise einmal nicht der Fall, so befriedigt jedenfalls eine nochmalige gleich starke Injection vollkommen unsern Zweck.

Jetzt spritze man mit scharfer Kanüle ca. $0,5 \mathrm{ccm}$ einer Lösung von $2 \%$ Pilocarpin direct unter den Sohlenballen einer Hinterpfote; ist die Injection beendet, trage man Vorsicht, die Stichöfnung mit einer Fingerspitze für kurze Zeit wenigstens zuzudrücken, damit nicht etwa unter dem erhöhten Druck des Gewebes die injicirte Masse z. Th. wenigstens ausfliesse.

Nach Kurzem, schon binnen 3 Minuten sieht man nun regelmässig auf der. Pilocarpinseite eine reichliche Menge kleiner Schweisströpfchen auftreten und wachsen dieselben mit der Zeit zu immer grösser werdenden Tropfen an. Die andere Seite dagegen zeigt fortdanernd keine Spur von Schweiss, selbst dann nicht, wenn mit stärksten tetanischen Strömen ${ }^{2}$ ) immer frische Nervenstrecken gereizt werden.

Das Atropin wirkt also jedenfalls auf der einen Seite noch in voller Stärke; wenn also auf der andern durch eine locale Gabe Pilocarpin sets ein dentlicher, oft sogar ein starker Schweissausbuch erfolgt, so muss eben jene local im Ueberschuss anftretende Menge des reizenden Giftes den lähmenden Stoff in seiner Wirkung wirklich aufzuheben im Stande sein, kann in der That sogar die auf $\mathrm{Null}$ gesunkene Erregbarkeit eines Organestrotz fortdauernder Gegenwart lähmender Stoffe durch reizende Mittel gleichwohl wiederum aufs Neue belebt werden.

1) Anstatt der ganzen Reihe unserer völlig übereinstimmenden Versuche sei auch hier nur ein einziger gleichsam als Muster nochmals vorgeführt.

2) Im primären Kreise befindet sich ein Daniell, die secundäre Rolle eines Schlittenapparates ist beinahe aufgeschoben. 
Die Wirkungen v. Muscarin u. Atropin auf d. Schweissdrüsen d. Katze. 503

Unsere Versuche sind in ihrer Ausführung so einfach und geben so sichere Resultate, dass man sie mit Fug als Vorlesungsversuche zur Demonstration eines wichtigen Princips empfehlen kann. -

Der Wunsch lag nahe, unsere gesicherte Erfahrung auch an andern Giften zu erproben. Wegen seiner dem Pilocarpin in so vielen andern Reziehungen nahverwandten Wirkungen schien uns Muscarin ${ }^{1}$ ) sehr geeignet zur Untersuchung.

Dasselbe wurde meist als Muscarinum sulphuric. angewandt.

In wenig Wasser gelöst und subcutan injicirt erregte auch Muscarin in der That gleichwie Pilocarpin mächtigen Schweiss auch auf der entnervten Pfote, erwies sich somit günstig zum Studium antagonistischer Giftwirkungen.

Die oben bei der Besprechnng der Pilocarpinwirkung ausführlich mitgetheilte Versuchsanordnung bleibt natïrlich hier vollkommen die gleiche. -

Ist ein Kätzchen mit gentigender Atropinmenge vergiftet, sodass selbst stärkste Reizung der Nerven keine Secretion mehr erzwingt, so kehrt.-gleichwohl bald darauf die Erregbarkeit des Hiuftnerven auf jener Seite wieder, wo eine locale Injection von Muscarin gemacht wurde; ja bald daranf - schon binnen $5 \mathrm{Mi}$ nuten - erfolgt auch hier spontaner Schweissausbruch, während die Controlpfote die ganze Zeit über selbst auf die stärksten Reizungen der Schweissfasern jegliche Spur von Schweiss versagt. Damit kann es sich offenbar aber nicht etwa um eine allgemeine, rasche Entgiftung von Atropin handeln ${ }^{2}$ ); vielmehr hat die local so beträchtlich gesteigerte Menge des reizenden Mittels auch hier local die lähmende Wirkung des Atropin a f gehoben. -

Nähere Einzelheiten auch dieser Versuche wird der Eine von uns demnächst in seiner Inauguraldissertation mittheilen.

1) Vgl. Schmiedeberg und Koppe, Das Muscarin. 1869.

2) Man erinnere sich des von Rossbach frühern, ähnlichen Versuchen entgegengehaltenen Einwandes. 